\title{
9 Transformations of European Public Spaces with AVs
}

Robert Martin, Emilia M. Bruck, Aggelos Soteropoulos

1. Introduction

2. Copenhagen design experiments on the sustainable deployment of AVs

2.2 From train station to mobility hub

2.3 A new dynamic streetscape

3. Conclusion

Literature

Robert Martin

JAJA Architects ApS, Copenhagen \& Aalborg University CPH, Department of Planning robert@ja-ja.dk

Emilia M. Bruck

TU Wien, future.lab Research Center and Research Unit of Local Planning (IFOER) emilia.bruck@tuwien.ac.at

Aggelos Soteropoulos

TU Wien, future.lab Research Center and Research Unit of Transportation System Planning (IVS) aggelos.soteropoulos@tuwien.ac.at

(C) Der/die Autor(en) 2021

M. Mitteregger et al. (Hrsg.), AVENUE21. Politische und planerische Aspekte der automatisierten Mobilität, https://doi.org/10.1007/978-3-662-63354-0_9 


\section{INTRODUCTION}

Connected and automated driving is one of several emerging mobility trends that will fundamentally impact the use and design of public spaces in the coming decades. The uptake of transportation network companies (TNCS), such as Uber, has shown that a greater use of shared modes adds more vehicles to the road and shifts pickup and drop-off locations onto the street, i.e., increasing activity at the curb (Larco 2018: 50; Erhardt et al. 2019). Similar effects were caused by recent waves of dockless micromobility options, such as free-floating bikes or e-scooters, which temporarily led to congested sidewalks and increased spatial demands in public space (Polis 2019). In effect, cities are challenged to rethink the exclusive rights given to cars within their mobility network. Ongoing mobility innovations and expected developments in automated mobility require a reallocation of public space and render existing categories of traffic division and regulatory frameworks outdated (Polis 2019: 12-13).

This article highlights possible trajectories for redesigning public spaces in a European context in order to illustrate urban futures in light of new mobility developments, such as automated mobility and a greater mix of traffic modes. To this end, this article views public space holistically, encompassing traffic infrastructure, public open spaces, as well as adjacent buildings. Considered as such, public spaces may comprise a variety of qualities, functions, and interests that differ, even diverge at times, depending on urban structure and street typology (Bendiks/ Degros 2019, Marsden et al. 2020, Karndacharuk et al. 2014). With automated mobility on the horizon, urban planners need to rethink whose interests they place at the center of their designs and what transport modes are given priority. While industry and policy representatives emphasize traffic advantages, such as safety and efficiency gains, spatial and social implications of automated use cases remain highly uncertain (see chapter 2).

While a number of design studies have been made that envision how public spaces could be transformed with automated vehicles, the majority of them refer to North American cities or no specific urban context at all (e.g., NACTO 2019, Schlossberg et al. 2018, Luo 2019, Sasaki 2018, Meyboom 2019). As a result, there is a lack of contextual design studies that highlight the specificity of urban form, mobility culture, and planning rationale. Just as "total designs" of the modern and postmodern era denied incremental growth of cities and pluralist decision-making (Venturi et al. 1977: 149), design visions for the ongoing mobility revolution need to take contextual factors into account in order to elucidate local implications-opportunities and risks-of new mobility technologies.

In contrast to most North American cities, many cities in Europe have high-density urban structures and compact historic cores. Many of those cities have urban transit networks that are well integrated into their urban fabric, providing the backbone of urban mobility. Beyond that, cities such as Amsterdam or Copenhagen are known for having high percentages of cyclists and pedestrians. While this applies to inner-city districts, it is less the case in urban extension areas developed since the 1950s and '60s or low-density suburban developments where public transport is often difficult to reach and basic services are less accessible by bicycle or foot (van Essen et al. 2009: 13; Alessandrini et al. 2015: 146; Gavanas 2019: 4). Finally, while North American cities are known for expansive off-street parking lots that enclose suburban shopping malls or carve voids into inner-city urban fabrics, European cities are faced with spatial constraints within their inner-city historical districts, where the existing intensity and diversity of uses put pressure on already limited public space (Marsden et al. 2020). 
As the early euphoria around automated vehicles' (AVs') near-term market introduction wore off due to technological setbacks, it became more apparent that a longer-term period of mixed traffic conditions lies ahead in which automated vehicles share roads with conventional vehicles and rely significantly on connected services (Mitteregger et al. 2020, Backhaus et al. 2019). During this transition period, AVs will not be operating on the entire road network, but rather on designated streets or confined (geofenced) areas at limited speeds, i.e., special operational design domains that define the functional boundary of level-4 AVs (SAE International 2018). As of yet few urban design studies have been made for European cities (e.g., Dijkstra/lonescu 2019, ARUP 2018); they largely show visions of level-5 AVs that assume AVs would operate within the entire traffic network and do not consider mixed traffic scenarios. It is, however, critical that urban planners and designers take into account a possibly long-term transitional period where there will likely be a need for strategies to manage the reallocation of curb space, a reclassification of street typologies and mode distribution, and the creation of transition zones where vehicles shift from automated to manual modes (Backhaus et al. 2019: 17).

To that end, design visions are a vital tool to support coordinated planning, decision-making, and development and ensure that public spaces remain a common spatial infrastructure contributing to quality of life in cities. This article introduces design experiments on possible public spaces with AVs, conducted by the Danish architectural firm JAJA Architects. Set in three varying urban areas within Copenhagen, Denmark, the designs build upon the specificities of local neighborhood structures and mobility requirements. Through plans and three-dimensional images, possibilities of integrating AVs into a sustainable transportation system are explored. By doing so, varying urban futures unfold.

\section{COPENHAGEN DESIGN EXPERIMENTS ON THE SUSTAINABLE DEPLOYMENT OF AVS}

The following design experiments take place within the northern European capital city of Copenhagen, Denmark. The city is an exemplary context in which to investigate how AVs may impact urban form as part of a sustainable transportation system because Copenhagen is already a model of green mobility. Within the Municipality of Copenhagen, $29 \%$ of all trips that either begin or end within its boundary occur by bicycle, $70 \%$ of households are car-free, and it has one of the most accessible public transport systems in Europe (City of Copenhagen 2017a, Scheurer 2013). While the city's comparatively sustainable transportation system is enviable, it did not happen overnight. Copenhagen has benefited from a rich planning tradition starting with the Finger Plan from 1947, where urban development proceeded parallel to five "fingers" centered on commuter rail lines, which extend from a "palm" of dense urban fabric within the Copenhagen municipal boundary (fig. 1). Subsequent investments in an underground metro system, as well as an extensive bicycle path network in the city center, have led to the Municipality of Copenhagen having one of the lowest per capita car emissions in the world (City of Copenhagen 2016). However, despite this, its current transportation system is far from secure. Political tensions in Copenhagen over the space allocated for cycling, cars, and public transport create continual backlashes and conflicts over street space, and the introduction of new mobility modes means that modal distribution is in constant flux (Henderson/Gulsrud 2019). How the introduction of $\mathrm{AVs}$ into this debate will affect modal share will be a result of social acceptance, policy, and spatial intervention. 
Figure 1. Copenhagen metropolitan plan with project locations. Municipality of Copenhagen highlighted in green with commuter rails (dashed) and metro (dotted).

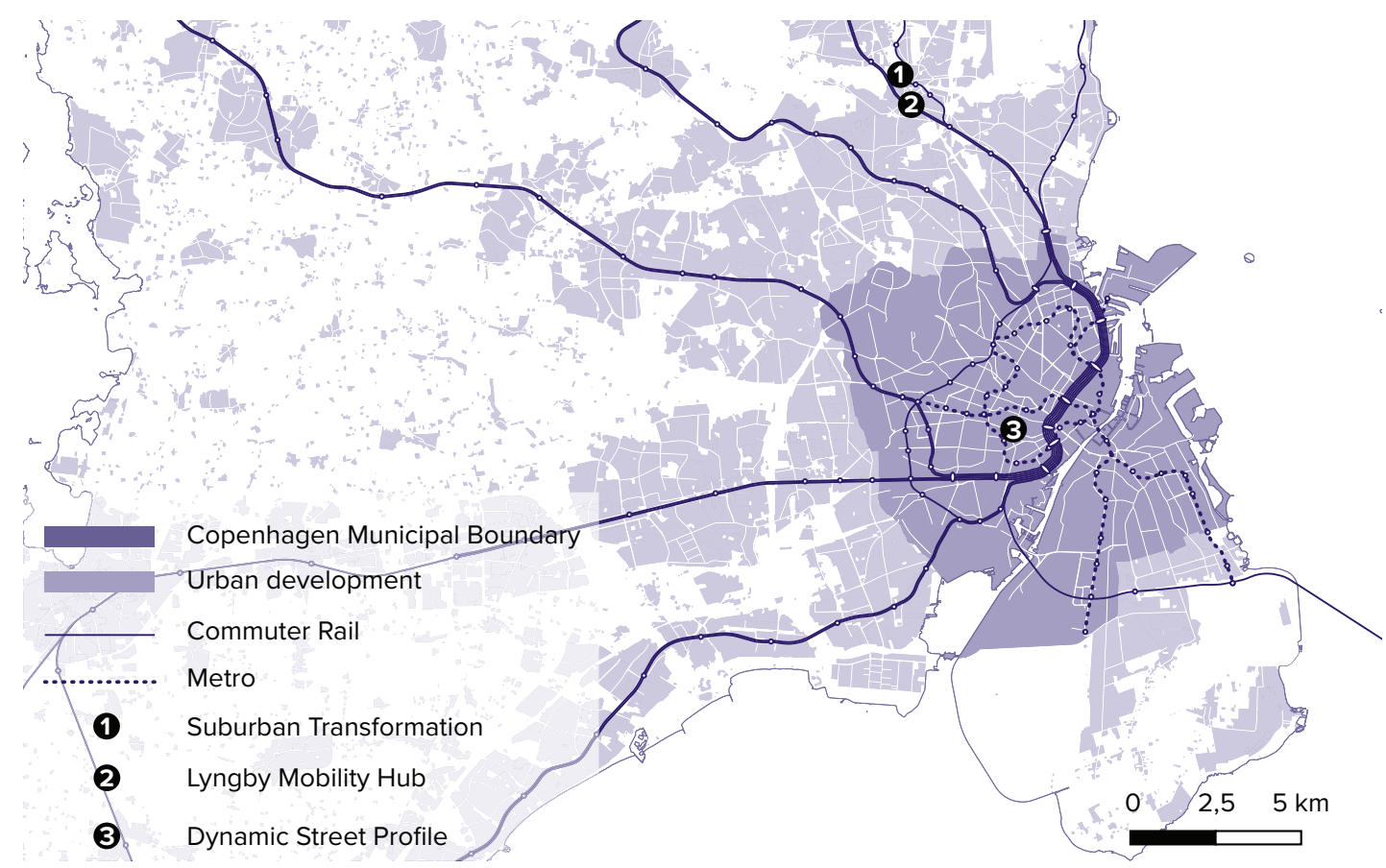

Source: JAJA Architects

As one moves along the fingers outside the municipal boundary, one finds a significantly different urban environment. Whereas only $7 \%$ of the residential building stock in the Copenhagen Municipality are single-family dwellings, this figure rises to $44 \%$ in the surrounding metropolitan region (Statistics Denmark 2019a). This dramatic change in spatial typology reflects a higher rate of car ownership (Statistics Denmark 2019a), sparser population density (Statistics Denmark 2020), and double the amount of space dedicated to road infrastructure per capita (Statistics Denmark 2016). While the primary consideration of AV introduction in the inner-city will regard preserving and promoting active forms of transport, the real spatial transformative potential of AVs lies in the surrounding suburbs.

To understand how urban form may be affected throughout the Copenhagen metropolitan region by the introduction of AVs, the authors have chosen a future scenario that is radically different from how transport is today. In this scenario, privately owned automobile use has been virtually nonexistent in the dense inner city since the Copenhagen Municipality banned private car use. Instead, residents and commuters move through a combination of public transport, fixed-route AV shuttles that run along arterial roads, and micromobility devices that range in size from kick scooters to electric cargo bicycles. Residents living in less dense suburbs outside of the inner city still have the option to own a car. However, most have chosen to adopt a taiIor-made Mobility-as-a-Service (MaaS) package that includes, among other offerings, an on-demand, free-floating AV shuttle that provides a last-mile connection to nearby public transport nodes. The technological development of AVs has reached a bottleneck and, therefore, they have only been deployed with Level 4 capabilities (SAE International 2018). This technical barrier means that $A V s$ may only operate within geofenced areas where the density allows for the commercial viability of creating and maintaining the high-definition 3D maps required for AVs to function safely. Therefore, motorized/conventional cars remain necessary for edge-case situations where AVs cannot operate, and traffic may be a mix of AVs and traditional automobiles. 
To visualize what effect this scenario may have on existing public spaces and streetscapes in Copenhagen, the authors offer three design studies in different urban contexts within the city. The first takes place in the suburb of Lyngby, approximately $10 \mathrm{~km}$ north of the city center, and investigates how a shift to a shared AV system may offer spatial opportunities to dissolve spatially segregated boundaries and provide communal amenities in an otherwise highly privatized monofunctional area. The second design study explores how the existing commuter rail station in Lyngby could be adapted to integrate an AV shuttle system with adequate space for pickup and drop-off that supports an efficient multi-modal transport system. The final design study investigates a modal space reallocation in an inner-city street where an increase in micromobility traffic places pressure on the spatial demands of a traffic artery used for a fixed-route AV shuttle.

\subsection{RETHINKING THE SUBURB}

While inner Copenhagen enjoys low car use, this dramatically changes as one moves into the surrounding suburbs where population density falls as single-family dwellings replace apartment buildings. The site of this exploration, the northern suburb of Lyngby, is a typical example. Despite enjoying excellent commuter rail connections and a decent bus service, this suburb still has over double the inner city's car ownership rate at 549 cars per 1,000 residents (Statistics Denmark 2019b). Compared to the inner city, which hosts an array of public and semi-public amenities on its streets, the suburbanization of Lyngby has created an urban condition wherein all functions occur within the boundary of the block, hidden behind high hedges or fences (fig. 7). This clear separation between public and private arenas has left the public realm somewhat vacant. Whereas in historical contexts, suburban streets would be full of playing children, now due to safety concerns the road lays empty, with only the occasional passing car, idling service van, or visitor's parked car (fig. 2). The division between private property and the public realm has become so stark that the only interface between the two is the driveway. A resident may, therefore, never actually physically touch the public domain, entering their vehicle within the boundary of their property before driving away to their destination.

Figure 2. Existing residential street. High hedges and narrow sidewalks represent a public space that is designed only for automobile use.

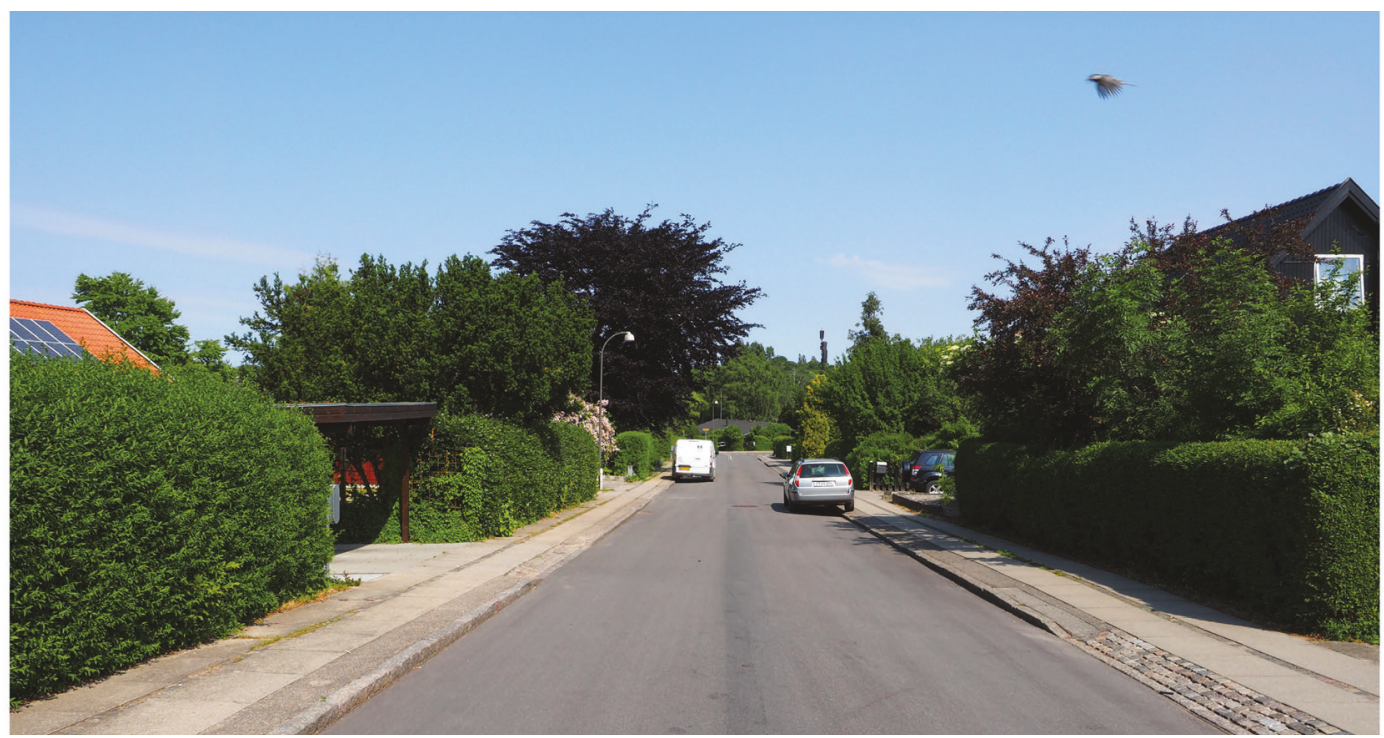

Source: JAJA Architects 
Figure 3. Proposed residential street. Life returns to the street as redundant road area is transformed into communal amenities. Fenced boundaries are dissolved as properties reconnect with the street's activities rather than blocking them out.

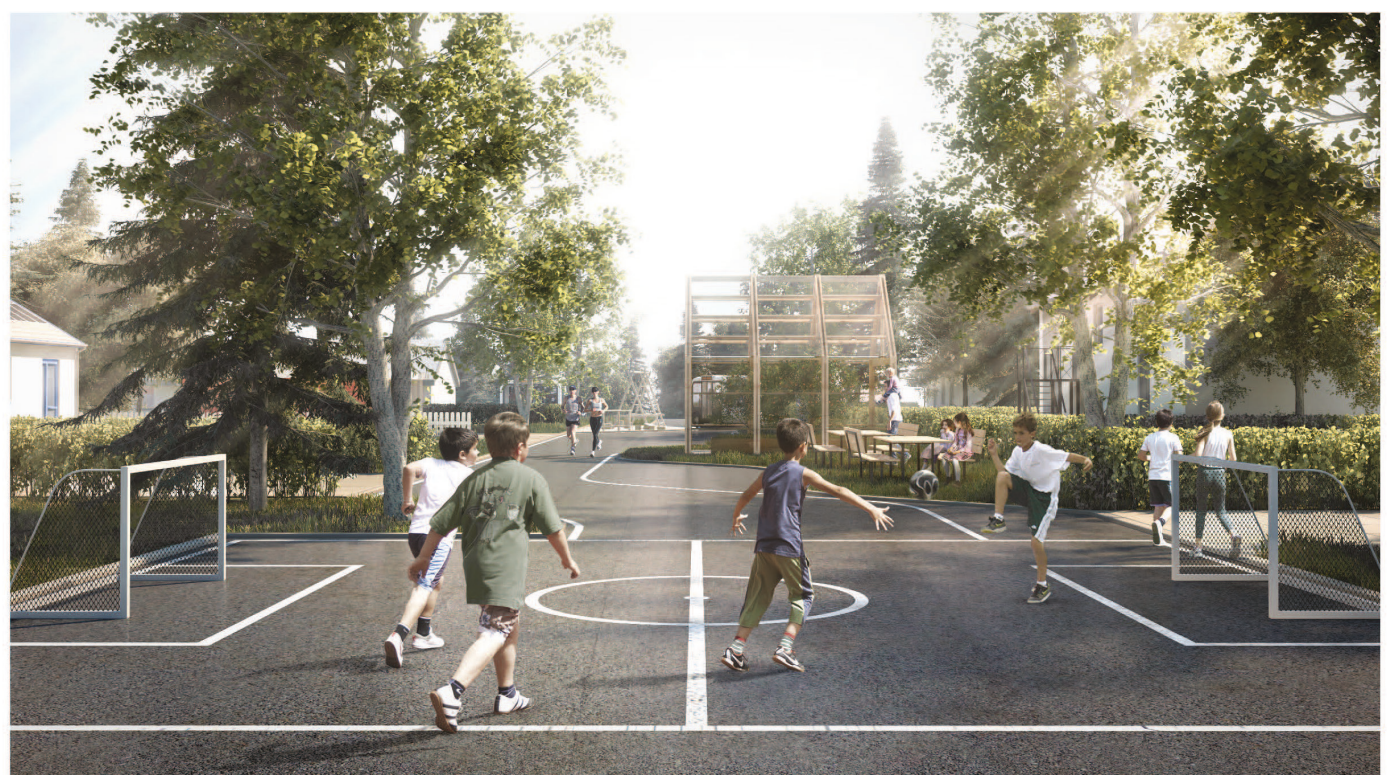

Source: JAJA Architects

JAJA's proposed adaptation to the street attempts to dissolve the suburban rationality of separation by spatially repurposing the abundant space given to automobiles in the road for new public amenities (fig. 3). The primary motivation behind this redistribution of space comes from both a radical decrease in traffic demand as residents shift from privately owned vehicles to shared AV shuttles and the technological ability of AVs to safely navigate intricate driving lines, always obey speed limits, and give way to pedestrians and children. Instead of providing a lane in each direction with enough room to overtake a parked car adjacent to the curb (fig. 4.), the road width is limited to that of a conventional single-vehicle lane for both traditional and autonomous vehicles.

The road then undergoes a series of manipulations to ensure that there a right of access to all existing driveways remains so that residents still have the option to own a private car, and that there is space for vehicles traveling in opposite directions to give way or pass each other (fig. 5). The residual space provides opportunities to install fixed amenities that both foster community, such as vegetable gardens, outdoor dining areas, community houses, or sport facilities, and support the new multimodal transport system, such as a covered waiting area for AV shuttle services and parking space for shared micromobility devices. The boundary of these new facilities is not limited to a demarcated area. Instead, through safely negotiated and temporal use, the facilities can spill out into the road area, better utilizing the space for active functions that can stop when a vehicle passes.

Through an increase in public amenities, an opportunity arises to renegotiate the threshold between public and private. With more functions becoming shared, the abundance of open space behind individual boundaries, especially adjacent to the street, are re-zoned to create new ancillary dwellings (figs. 6 and 8). These new dwellings vary in ownership models and typology, with many of the functions outsourced to the communal facilities to attract a diverse range of new residents not suited to the homogenous rows of single-family dwellings otherwise found in the area. The increase in population would drive demand for AV shuttles, reducing the operating costs of the system while increasing the efficiency and desirability of the system. 


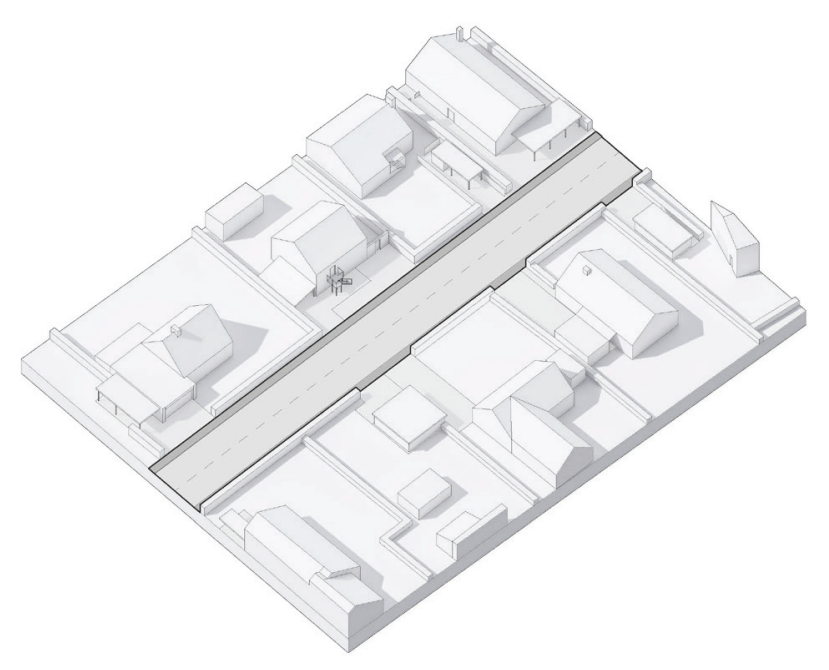

\section{Figure 4. Existing street design}

Existing street axonometric. The majority of the streetscape is dedicated to car use.

Figure 5. Expansion of public space

By reducing the street profile to one way, but still providing spaces to overtake and connect to driveways, new pockets of space can be designated for communal amenities.

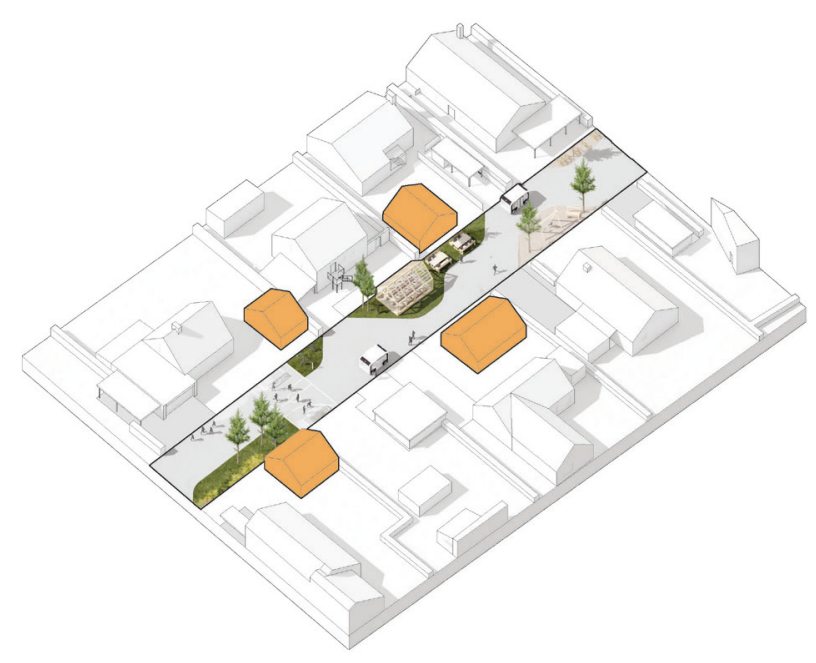

Figure 6. Programming

New ancillary dwellings are placed adjacent to communal activity areas to dissolve the boundary between public and private along the street. 
Figure 7. Existing site plan. A grid of single-family homes and garages separated by a field of fences and streets.

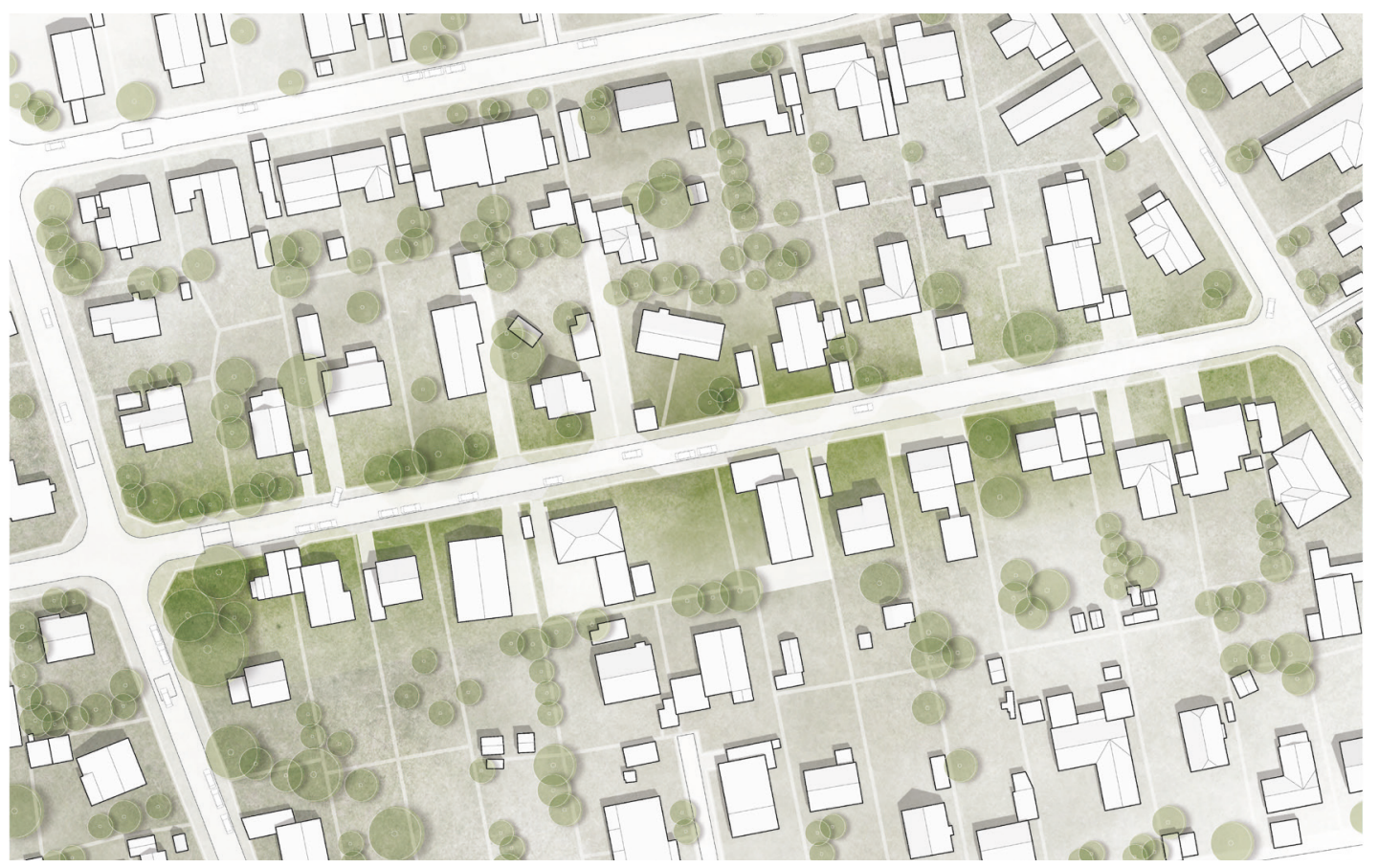

Source: JAJA Architects

Figure 8. Proposed site plan. Newly inserted buildings and functions operating at different scales disrupt the grid and create a gradient of zones with different levels of privacy.

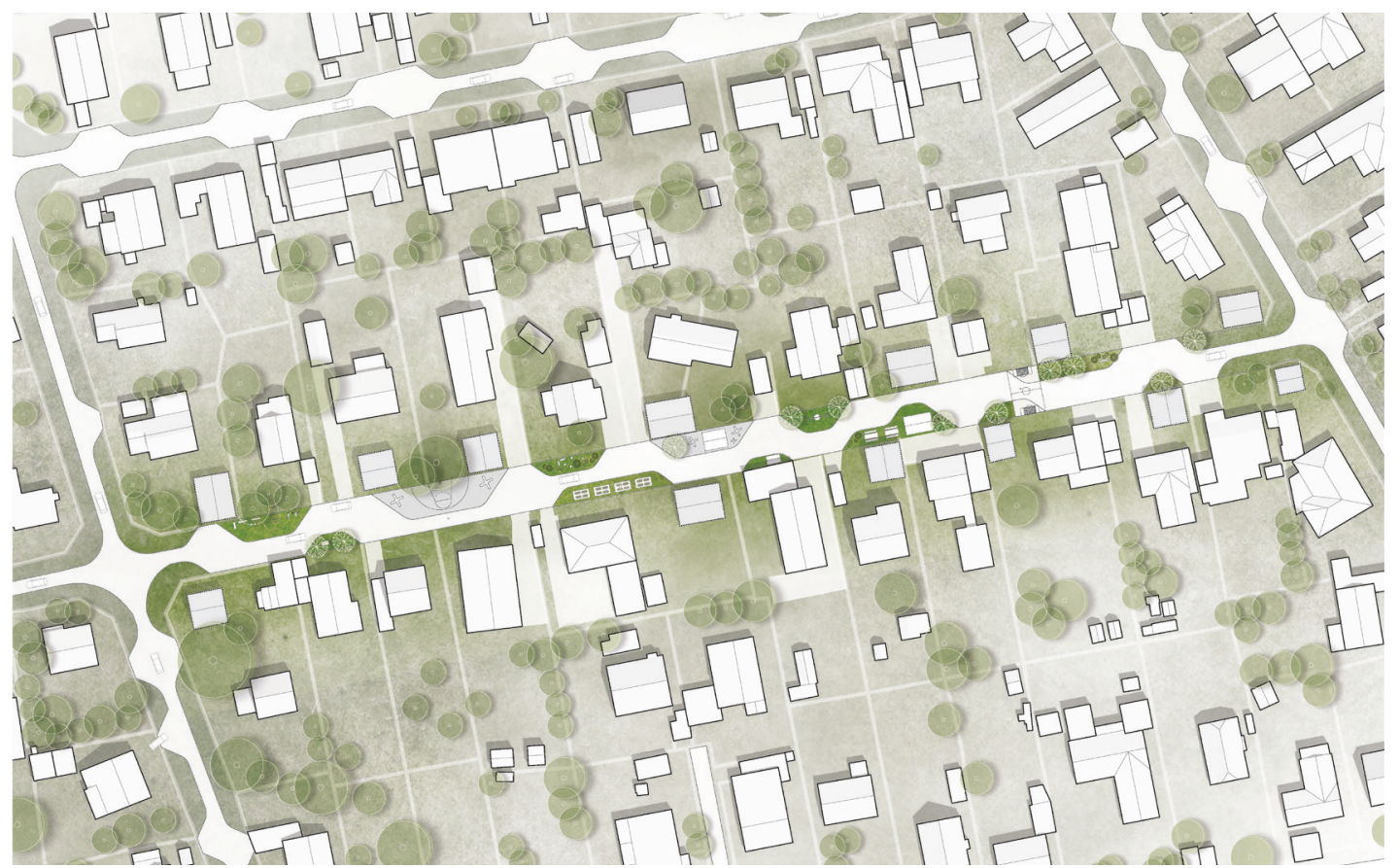




\subsection{FROM TRAIN STATION TO MOBILITY HUB}

Multimodal transport routes are often proclaimed to be the sustainable alternative to car trips, where commuters shift between higher and lower-capacity modes to reach their destination. However, this system is reliant on the proximity to transport nodes and available connecting routes only found in higher-density urban fabrics. The challenge of transporting commuters to network nodes in lower-density suburbs is referred to as the first/last-mile gap. Shared AV shuttle systems, as used in the previous design example, are often discussed as one solution to this common problem. Conceptually, this system operates similarly to already established car-pooling services such as Uber, Lyft, and Via, where users' ride requests are bundled and assigned into trips with similar pickup and drop-off points. However, the success of these services is highly dependent on population density, the concentration of users, and the similarity of users' departure and arrival points and times. By focusing the departure or arrival point around public transport nodes, the shared AV shuttle system's efficiency is improved by accumulating similar trips. Nevertheless, points of friction are likely to occur at the interchange between modes as existing transport infrastructure has not been designed to enable AVs. The following design explores how adaptations to the existing train station at Lyngby can spatially support this new technology as users seamlessly transfer between AV shuttle and high-capacity train.

The existing Lyngby station is a train station on the Hillerød radial of the Finger Plan. It is centrally located within the suburb but is spatially segregated from the suburb's high street and mass of urban functions by a large bus terminal, two lanes of traffic, parking lots, and an elevated highway to the east (figs. 9, 11, and 14). The station's entrance is located underneath the highway, where it is also connected to a shopping center with 15 retail stores, including two supermarkets.

Figure 14. Existing site plan. The station is separated from the suburb's high street (running from top left to right of image) by multiple roads, parking lots, a bus terminal, and an elevated highway.

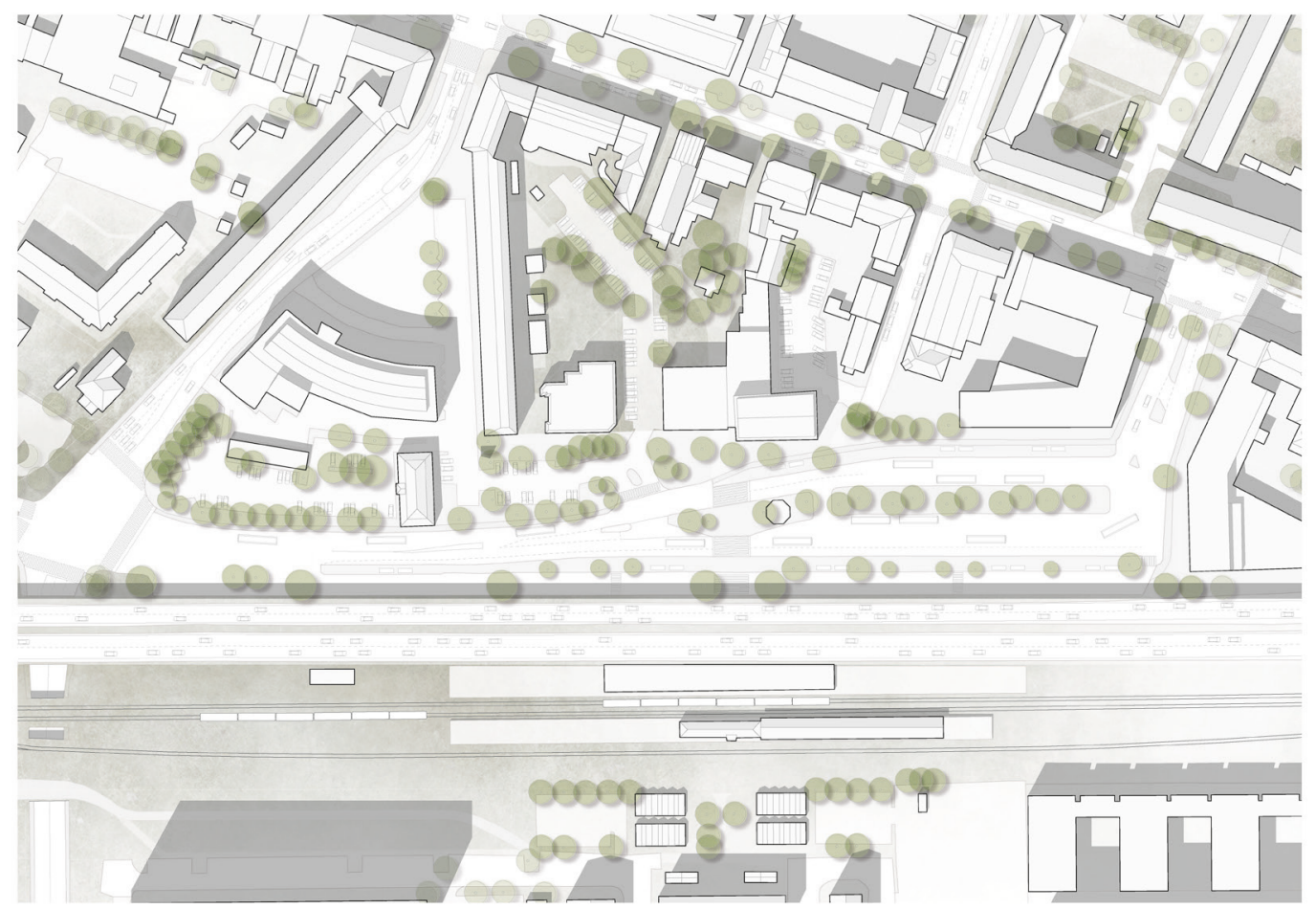


Figure 9. Existing street view at Lyngby station. Commuters are separated from the station entrance by a series of roads that must be crossed in sections.

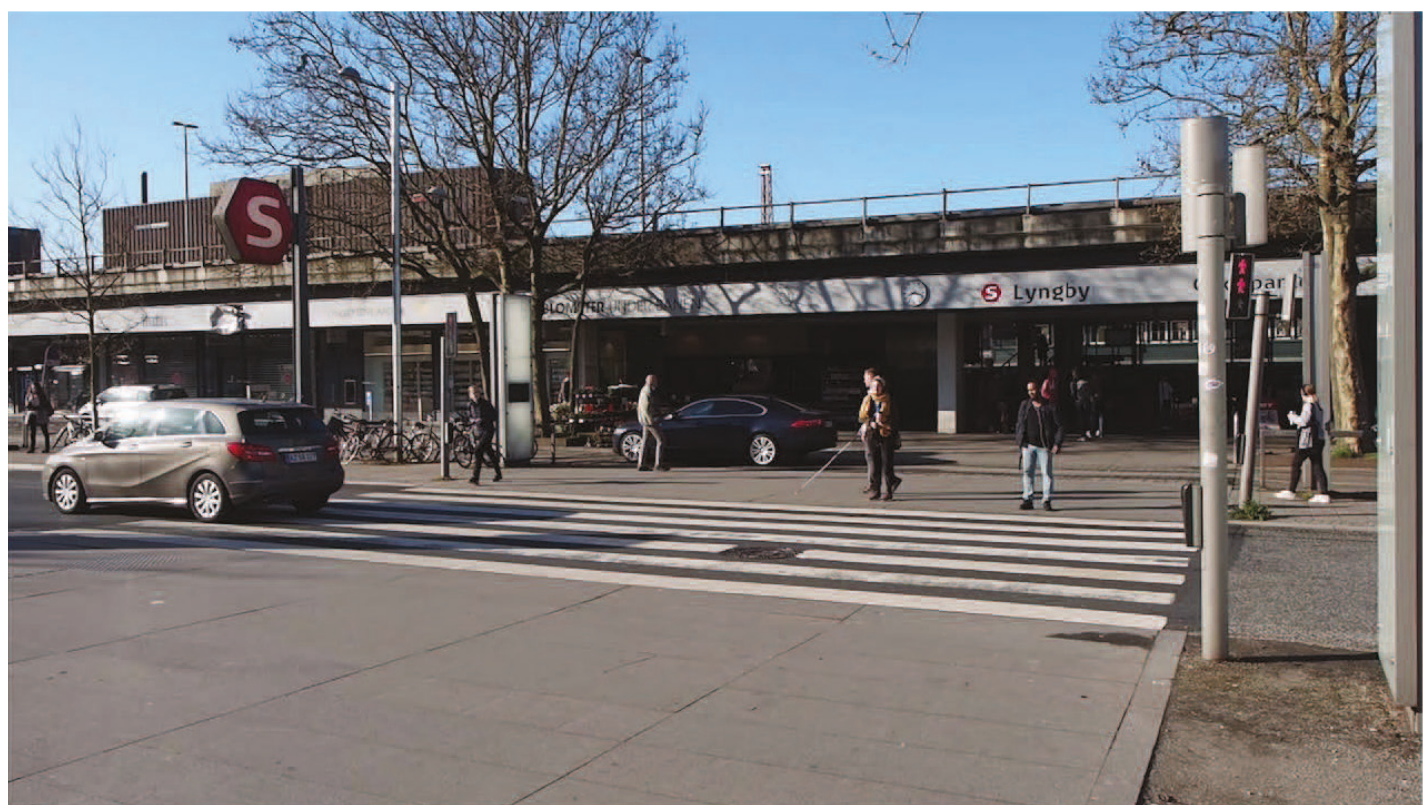

Source: JAJA Architects

Figure 10. Proposed street view at Lyngby station. A permeable station edge allows commuters to enter the stations from multiple points while an information-rich digital screen provides wayfinding connections to standing by AV shuttles.

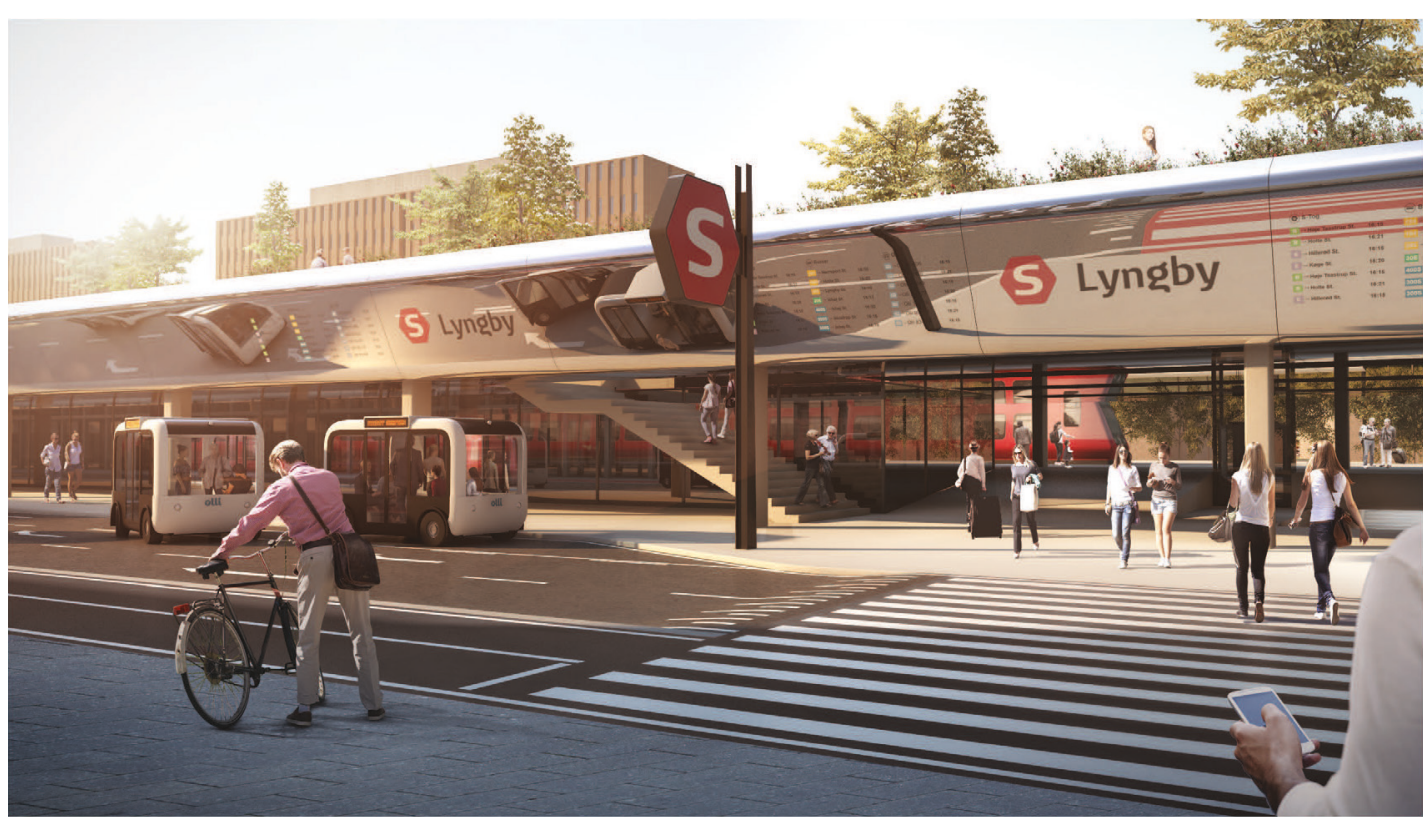



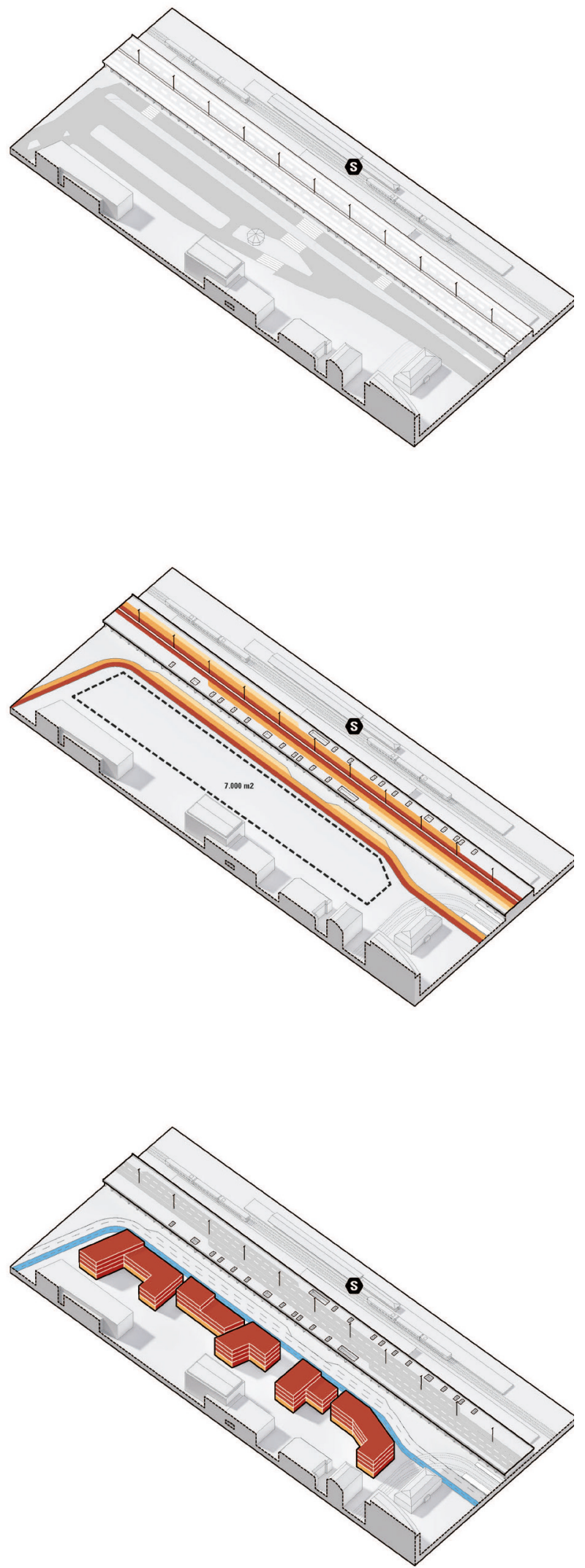

Figure 11. Existing station design

The existing station axonometric highlights the many obstacles to enter the station.

Figure 12. Redistribution of infrastructure

Pickup/drop-off areas are condensed into two areas: the first area lies adjacent to the station entrance while the second is located on the elevated highway.

Figure 13. Urban infill and densification

New mixed-use development is situated in the publicly owned former bus terminal. The new development not only adds spatial qualities and increases density, but the revenue from the development can be utilized by the municipality to fund public programs. 
The primary design challenge for this proposal was to create adequate space for the pickup and drop off areas for commuters arriving by AV shuttles. While many advocates for AVs suggest that excess parking space will be released from sharing these vehicles, studies have shown that the spatial requirements for pickup and drop-off areas will be high as they should be designed to accommodate maximum inflow at peak times (Sinner et al. 2018). Therefore, the main decision made in the design is to consolidate the seven lanes of traffic that run in both directions adjacent to the station into one $150 \mathrm{~m}$ long designated area for transfers (fig. 12). This area follows design principles found at airport kiss-and-ride locations where one lane is used for parking (colored light orange), one is used to wait for a free space (colored orange), and the final one is used to pass by when finished (colored red). Due to a dramatic decrease in traffic demand from sharing and AV platooning, as well as increased safety from connected vehicles, this principle is replicated on the elevated highway, which runs directly above the train station entrance. Cuts in the structure create vertical movement between the highway and the station, allowing more accessible routes to the station for residents who have to access it from the west.

Figure 15. Proposed site plan. A new mixed-use development completes the urban block, utilizing the former bus terminal. AV shuttle pickup and drop-off areas have been consolidated to be directly adjacent to the station and on the reduced-capacity highway.

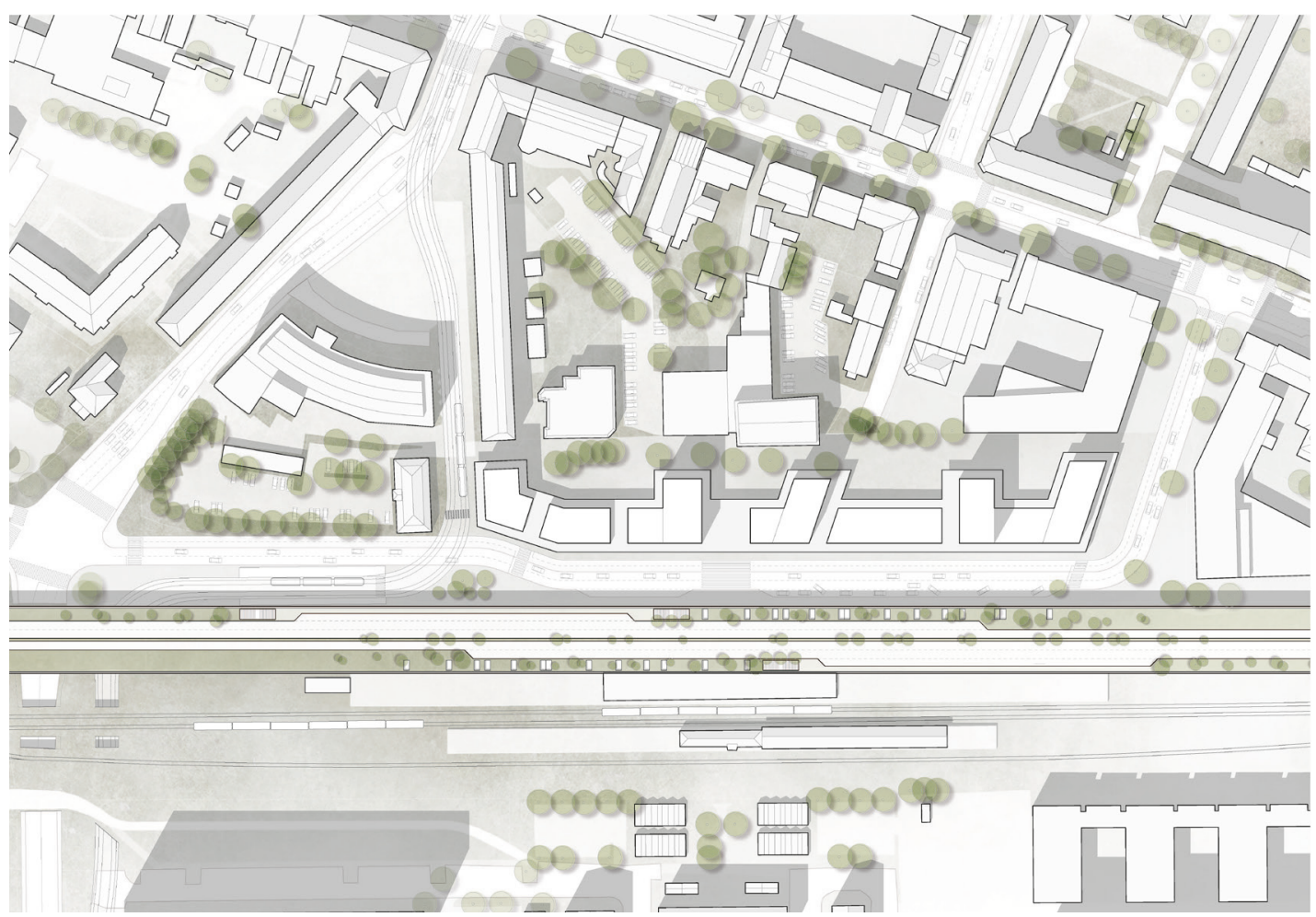

The spatial benefit of this consolidation is the release of over $7,000 \mathrm{~m}^{2}$ of publicly owned land directly adjacent to the train station. In this proposal, that space is utilized by constructing a mixed-use development of residential apartments, commercial space, public amenities, as well as parking facilities for micromobility devices adjacent to new separated bicycle paths (fig. 13). The proposed development takes its form by closing the urban block to the east, creating a 
series of public and semipublic courtyards of varying scales that respect the existing pathways between the station and the high street (fig. 15). The final move is to relocate the shopping center from underneath the highway to the new mixed-use development. The now vacant space is transformed into a permeable covered thoroughfare that gives access to the station platforms directly from the pickup/drop-off area. There are also seated waiting areas and digital wayfinding screens that help commuters find their designated shuttle (fig. 10).

\subsection{A NEW DYNAMIC STREETSCAPE}

Unlike the suburbs of Copenhagen, where road space is abundant due to car-centric planning principles since World War II, the inner city has to negotiate modal allowance within a narrow spatial context designed centuries before the invention of the car. Subsequent additions of transport modes have constrained pedestrian sidewalks and cycle paths to minimal widths. At the same time, two-way roads, car parking, and bus stops occupy the majority of space between buildings. Within inner Copenhagen, only $7 \%$ of citywide road space is taken up by cycle paths. In contrast, road space for cars amounts to 66\% (City of Copenhagen 2017b), even though modal trips are split almost evenly between bicycles and cars. Overcrowding on cycle paths is already a severe problem in Copenhagen and a significant impediment for increasing the city's incredibly high levels of cycling (Danish Parliament 2016). Unfortunately, it is not merely an option to widen cycle paths on artery roads as the constrained context is filled by the spatial provision of on-street car parking. AVs promise to release this space through the logic of never having to park (Duarte/Ratti 2018). However, this logic ignores the new spatial demands of $A V s$. We expect that $A V s$ will increase door-to-door mobility and will, therefore, require equal space to embark or alight from the vehicle.

The conflict between AVs and cycle paths has given rise to significant design considerations in JAJA's urban scenario below, where a projected substantial increase in modal share by micromobility devices has resulted from the banning of privately owned vehicles in the city center. The street under investigation is Gammel Kongevej (fig. 16), which is one of the principal shopping streets in Copenhagen and dates back to the beginning of the 17th century. The street extends for $1.8 \mathrm{~km}$ from the western edge of the city center and provides a direct connection to the western suburbs. The street is only $18 \mathrm{~m}$ wide from one building façade to the other, so it currently utilizes a three-lane system to accommodate all the spatial demands from different modes. One lane each is dedicated to vehicle traffic in either direction; a third lane is located in an alternating manner on either side to allow for curbside parking and for buses to stop (fig. 18). While this system provides space for vehicle modes, it is an underutilization of space (fig. 19), and the spatial implication of these fixed infrastructures means that cycle lanes along the street are below the legal minimum width at only $1.5 \mathrm{~m}$ (fig. 21; City of Copenhagen 2013). How then could pickup/drop-off areas be integrated into this already crowded street while allowing an extension in the width of cycle lanes to meet increased travel demand by micromobility services? 
Figure 16. Existing street view along Gammel Kongevej. A man quickly enters a stopped bus moments before cyclists are due to pass

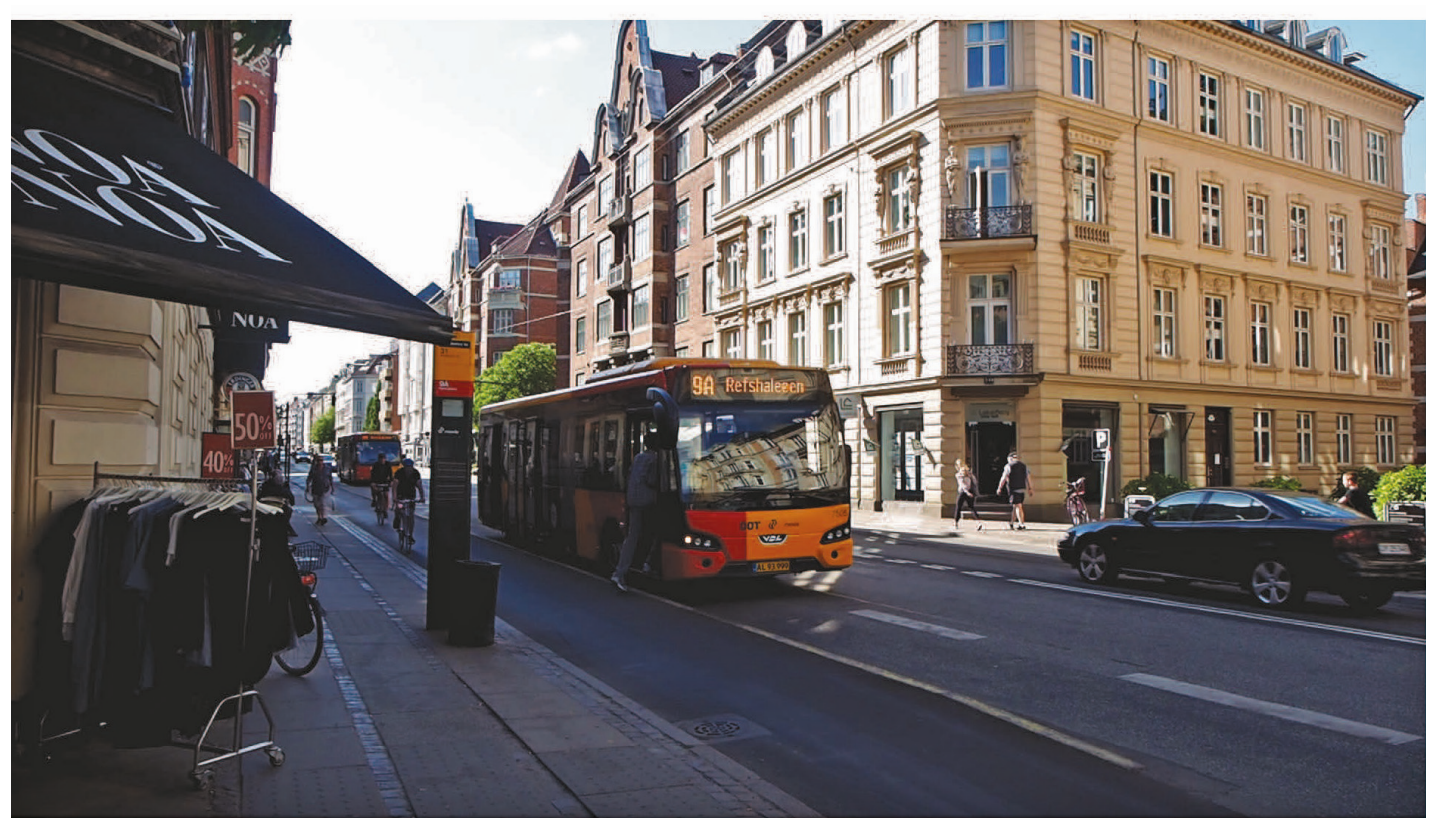

Source: JAJA Architects

Figure 17. Proposed street view along Gammel Kongevej. A man safely departs his AV shuttle onto the dynamic street surface, knowing that the coming cyclist will pass outside the boundary of his designated area.

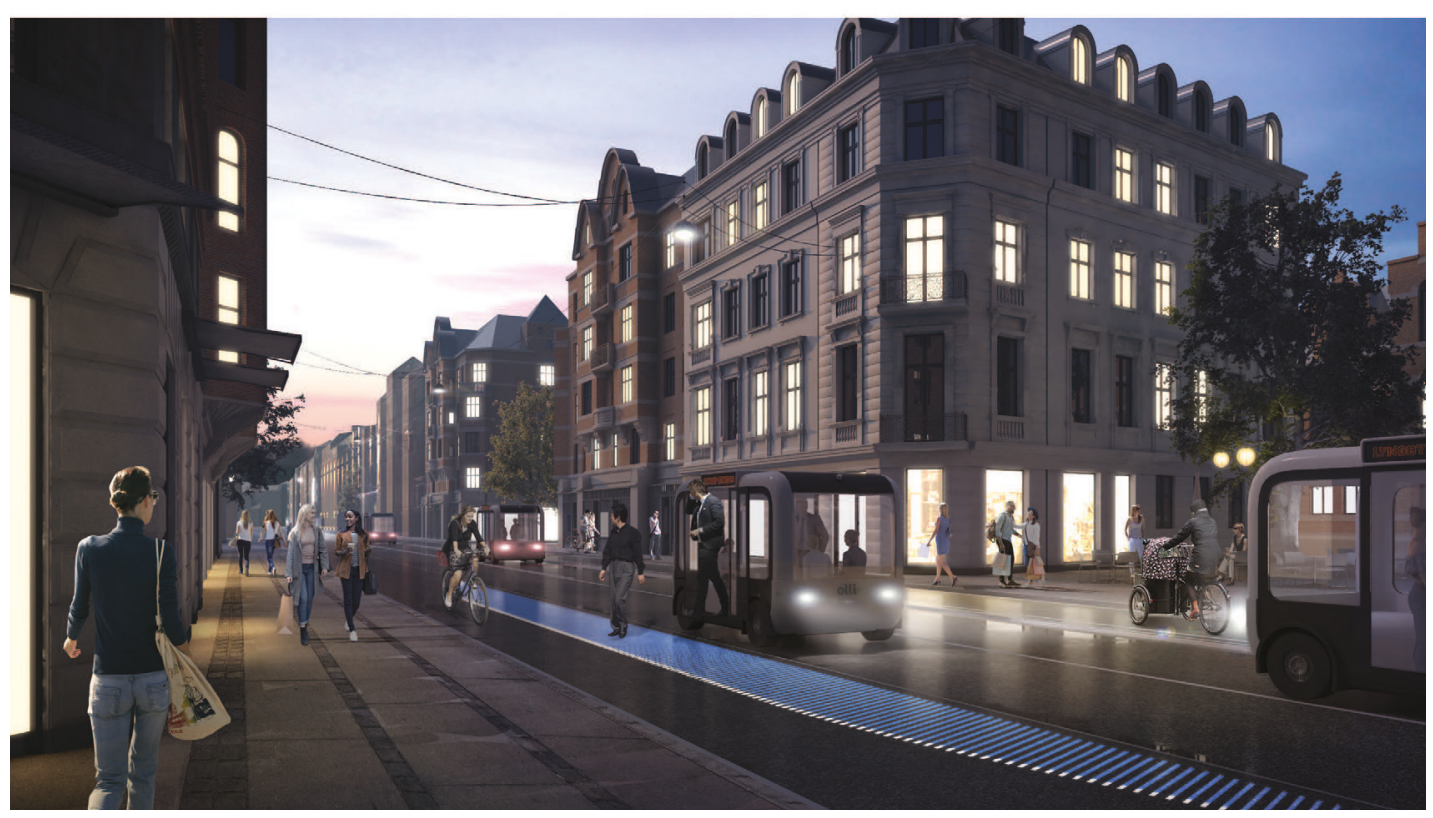




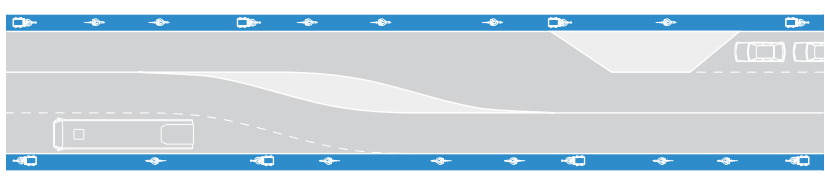

Figure 18. Existing street design

Existing zone plan of the street highlighting the spatial preference toward automobiles over bicycles regardless of their equal modal share.

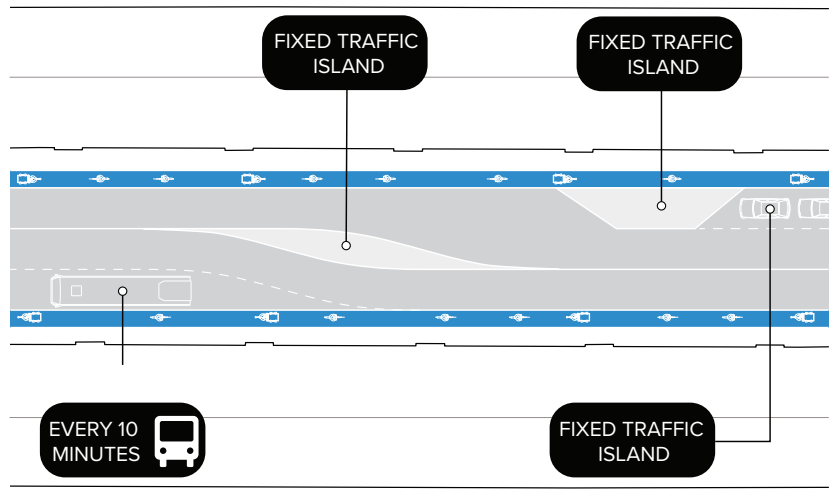

Figure 19. Functional requirements

Analysis of function demand. Fixed spatial infrastructures underutilize the space.

Figure 20. Dynamic street design

Rather than have a fixed shuttle stop, dynamic hop-on/hop-off areas can pop up along the street as user, vehicle, and road surfaces are connected through the IoT. 
This design proposal utilizes advancements in the Internet of Things (IoT), where embedded sensors, lights, and transmitters allow vehicles to communicate with road infrastructure. Rather than having fixed street infrastructure that designates where certain functions should occur, the streetscape is enhanced with a grid of LEDs that can reallocate space in accordance with changing traffic volumes. Fixed on-street parking and bus stops are removed, allowing the third lane of the street to no longer be needed, and that space is redistributed to widen the cycle lanes to $3.5 \mathrm{~m}$ in both directions (fig. 22). AV shuttles do not have fixed stopping points but are free to stop anywhere along the road (fig. 20). When a user makes a request to be picked up or dropped off, GPS coordinates of the location are communicated between the mobile device, AV shuttle, and the road in preparation for the stop. As the AV shuttle approaches the destination, the road surface changes at the threshold between the road and cycle path to indicate a buffered area where passengers will alight and gives safe notice to incoming micromobility devices to avoid the buffered area. Modes using the cycle path will continue to have right of way, although half of their expanded lane will now be demarcated as a buffered passenger zone (fig. 17). Enforcement of this buffered zone is enabled through sensors in the road that track infringements through in-vehicle unique identifiers (UID). These road sensors monitor the user's duration in the buffered zone, and the road surface only returns to normal once the user has left the area. It is important to note that in this design, priority is given to modes using the cycle path, so this form of traffic is not halted due to AV service. Modes using the cycle path will have the right of way, while AV shuttles will stand on the road rather than adjacent to the curb, knowing that other connected AV shuttles will anticipate the stop and wait or re-route if necessary.

Figure 21. Existing street plan. Commuters entering and exiting the bus are placed in conflict with cyclists. Although cyclists are required to give way to commuters, this law is often ignored because of lost inertia.

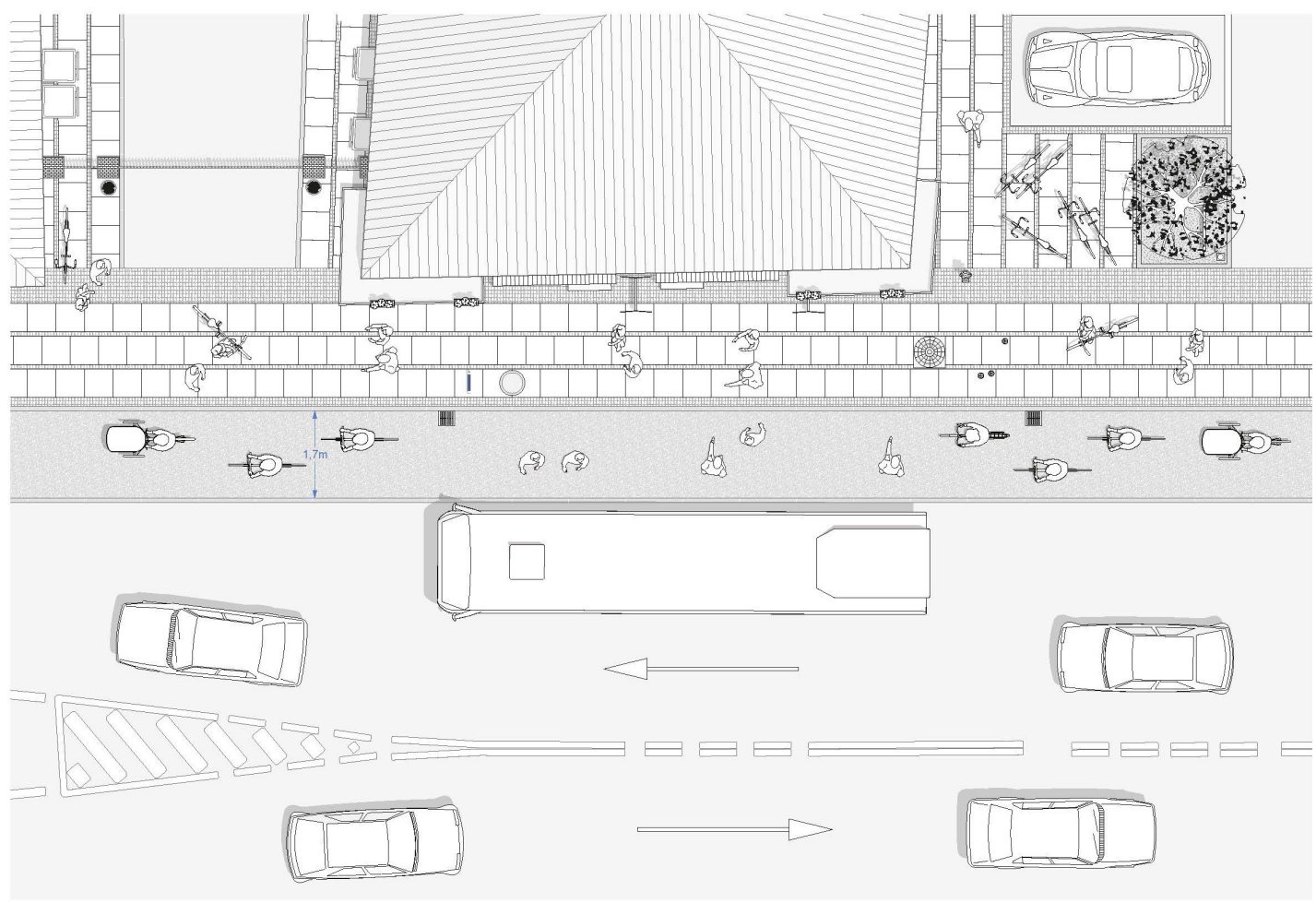

Source: JAJA Architects 
Figure 22. Proposed street plan. The removal of one lane of traffic has allowed the bicycle lane to be doubled in width. The new road surface is embedded with loT-connected LEDs that can create temporary buffered zones to allow users to safely enter and exit AV shuttles that still allow bicycles to pass by.

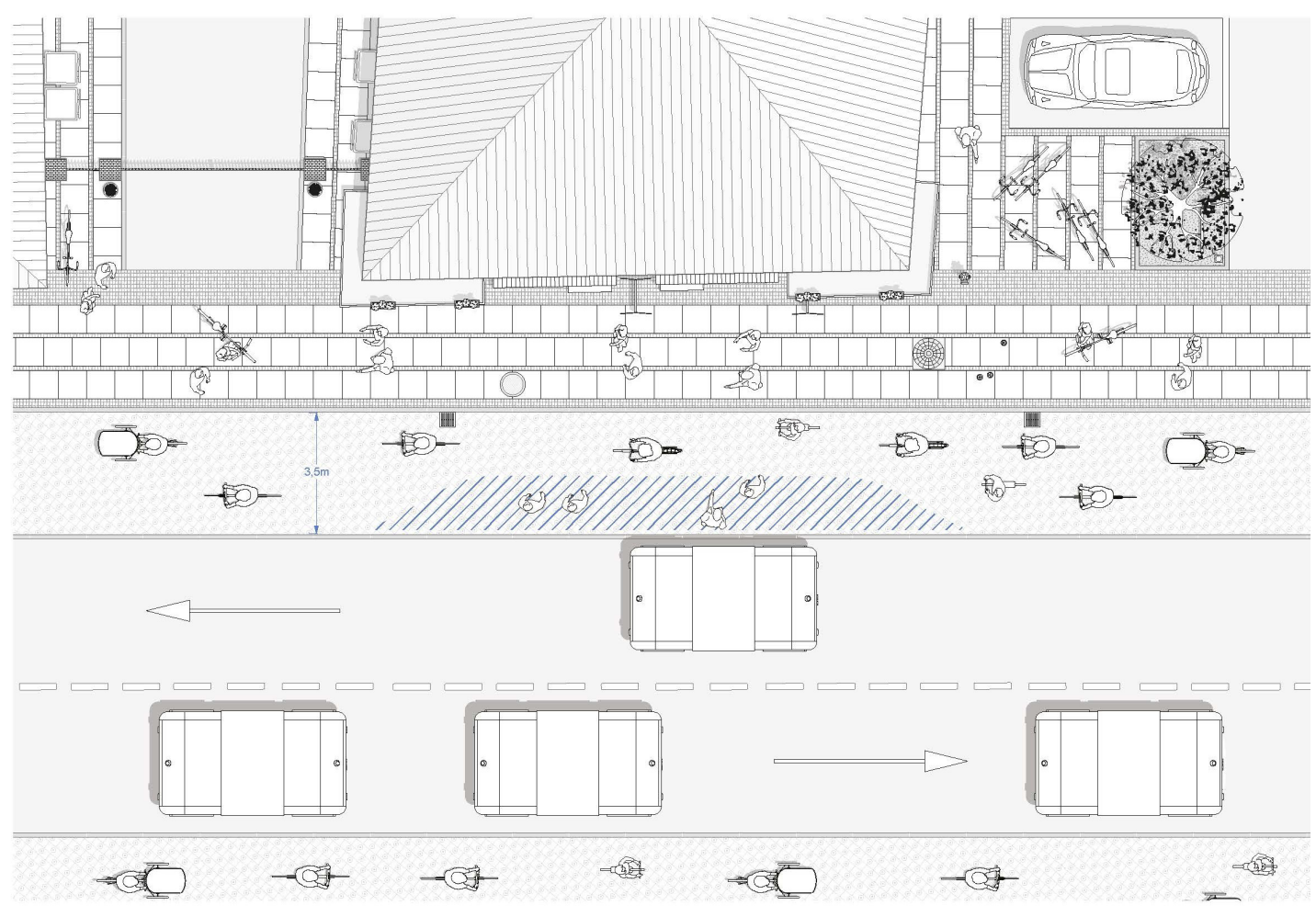

Source: JAJA Architects

\section{CONCLUSION}

This article presents design experiments on possible public spaces with AVs, i.e., how AVs may contribute to changes in urban form if integrated as part of a sustainable transportation system. The design experiments were set in three different areas within Copenhagen, Denmark, and focused on:

1. How a shift to a shared AV system could present an opportunity to dissolve spatially segregated boundaries and provide communal amenities in an otherwise highly privatized monofunctional area in the suburb of Lyngby

2. How an existing commuter rail station in Lyngby could be adapted to integrate an AV shuttle system with adequate pickup and drop-off areas that support an efficient multimodal transport system

3. How the reallocation of space toward active travel modes could take shape in an inner-city street of Copenhagen, where increasing micromobility traffic aggravates the pressure of spatial requirements on a traffic artery used for a fixed-route AV shuttle. 
These design experiments highlight that changes in urban design and infrastructure development related to the introduction of automated mobility services may vary significantly according to urban form and street typology. The functional requirements of a street design vary within a city and are determined by factors such as adjacent land use types, position within the urban street network, diversity of travel modes and users, as well as designated speed limits.

Due to the expectation that automated vehicles could generate greater demand, the pressure on street designs to facilitate higher numbers of vehicles per hour could increase (Larco/Tierney 2020). Thus, competing demands for street space might be aggravated in the future. The urban design challenge will rest even more than today in finding a suitable balance between catering to demands for more efficient movement and demands for attractive spaces. This is especially the case on inner-city streets where competing spatial demands are already high and heterogenous. Dynamic solutions, e.g., demand-based hop-on/hop-off areas, as presented in the design experiment for an inner-city street in Copenhagen, could pose a design-based measure that complements mobility management policies.

However, determining factors for adequate design interventions are highly contextual, both in material and political terms, and therefore require well-attuned solutions. To this end, local design experiments are critical in envisaging how to reallocate potentially freed-up space-due to a reduction in on-street parking-and tap into urban development potentials. As cities need to reevaluate the prioritization of modes and find solutions to safe mode interaction, design visions can elucidate the benefits of street design changes for the urban environment and surrounding land use. This also includes the question of how to spatially integrate modes and enhance a multimodal transport system, as shown in the design experiment on the transformation of the Lyngby train station into a mobility hub. Visualizing potential changes can serve as a critical tool that supports negotiation and collaboration between affected stakeholders or contrasting interests.

In addition, considering the long-term transition period leading toward automation, it is critical to reflect upon which changes could be implemented irrespective of vehicle automation and which changes need further investigation. Short-term issues that cities should address include strategies for curb management, prioritizing pickup and drop-off zones over on-street parking, increased cycling and micromobility lanes, as well as enhancing the integration between shared mobility and transit networks. While the influx of new mobility options is at a peak and the prospect of automated mobility does not appear to be fading, uncertainties regarding any trend's durability prevail. As a means of acting in uncertainty, cities are increasingly adopting pilot projects. Not merely to test AVs (see chapter 6), but also in order to test nighttime pickup and drop-off zones (Washington, D.C.), clearing curbs from commercial loading during designated times of day (New York City), or geofencing streets with high levels of active mobility interaction so as to avoid conflict with ride-sourcing services (San Francisco; Schaller 2019).

What is lacking are more comprehensive programs that would usher in the transition from public spaces characterized by parked cars and travel lanes to those that can be used flexibly and cater to shared modes. However, in order to develop guidelines on spatial requirements of new mobility options such as shared automated vehicles, further research and more comprehensive studies are necessary. Questions regarding the spatial demand for pickup and drop-off activities or short-term parking need more thorough investigation through simulation and modeling. However, these should be developed in collaboration with design methodologies and visualizations that are better able to integrate the context of local development goals and neighborhood characteristics. 


\section{LITERATURE}

Alessandrini, A., A. Campagna, P. Delle Sitte, F. Filippi, and L. Persia 2015. "Automated Vehicles and the Rethinking of Mobility and Cities," Transport Research Procedia 5, 145-160. https://doi.org/10.1016/j. trpro.2015.01.002.

ARUP 2018. FlexKerbs. Evolving Streets for a Driverless Future, report, London. https://www.arup. com/-/media/arup/files/publications/f/flexkerbs_roads-for-the-future_arup.pdf (Mar 23, 2020).

Backhaus, W., S. Rupprecht, and D. Franco 2019. Road vehicle automation in sustainable urban mobility planning, practitioner briefing, Cologne. https://www.eltis.org/sites/default/files/road_vehicle_automation_in_sustainable_urban_mobility_planning_0.pdf (Aug 19, 2020).

Bendiks, S. and A. Degros 2019. Traffic Space is Public Space: A Handbook for Transformation. Zurich: Park Books.

City of Copenhagen 2013. Focus on cycling: Copenhagen guidelines for the design of road projects, trans. Joan Høberg-Petersen, Copenhagen. https://kk.sites.itera.dk/apps/kk_pub2/index.asp?mode=detalje\&id=1133 (Aug 4, 2020).

City of Copenhagen 2016. CPH 2025: Climate Plan. Roadmap 2017-2020, Copenhagen. https://urbandevelopmentcph.kk.dk/artikel/cph-2025-climate-plan (Aug 4, 2020).

City of Copenhagen 2017a. Copenhagen: City of Cyclists. The Bicycle Account 2016, Copenhagen. https://kk.sites.itera.dk/apps/kk_pub2/index.asp?mode=detalje\&id=1698 (Aug 4, 2020).

City of Copenhagen 2017b. Cycle Track Priority Plan (2017-2025), Copenhagen. https://idekatalogforcykeltrafik.dk/wp-content/uploads/2019/05/cykelstiprioriteringsplan-2017-2025pdf-_1620.pdf (Aug 4, 2020).

Dijkstra, R. and A. I. Ionescu 2019. "Streets and Robocars," in Robocar and Urban Space Evolution: City changes in the age of autonomous cars, edited by A. I. Ionescu, V. M. Sanz, R. Dijkstra. TU Delft, 31-39.

Erhardt, G. D., S. Roy, D. Cooper, B. Sana, M. Chen, and J. Castiglione 2019. "Do transportation network companies decrease or increase congestion?." Science Advances (5) 5, eaau2670. https:// doi.org/10.1126/sciadv.aau2670.

Gavanas, N. 2019. "Autonomous Road Vehicles: Challenges for Urban Planning in European Cities," Urban Science (3) 61, 1-13. https://doi.org/10.3390/urbansci3020061.

Henderson, J., and N. M. Gulsrud 2019. Street Fights in Copenhagen: Bicycle and Car Politics in a Green Mobility City. London/New York: Routledge.

Karndacharuk, A., D. J. Wilson, and R. Dunn 2014. "A Review of the Evolution of Shared (Street) Space Concepts in Urban Environments," Transport Reviews 34 (2), 190-220. https://doi.org/10.1080/014 41647.2014.893038.

Larco, N. 2019. "Urbanism Next: Autonomous Vehicles and the City," in Robocar and Urban Space Evolution: City changes in the age of autonomous cars, edited by A. I. Ionescu, V. M. Sanz, R. Dijkstra. TU Delft, 47-53.

Larco, N. and G. Tierney 2020. "Impacts on Urban Design," in Multilevel Impacts of Emerging Technologies on City Form and Development, edited by A. Howell, K. Lewis Chamberlain. Portland, OR: University of Oregon, 115-141.

Luo, Y. 2019. "From Transportation Infrastructure to Green Infrastructure-Adaptable Future Roads in Autonomous Urbanism," Landscape Architecture Frontiers (7) 2, 92-99. https://doi.org/10.15302/JLAF-20190209.

Marsden, G., I. Docherty, and R. Dowling 2020. "Parking futures: Curbside management in the era of 'new mobility' services in British and Australian cities." Land Use Policy (91), 104012. https://doi. org/10.1016/j.landusepol.2019.05.031.

Meyboom, A. L. and L. Vass 2019. Driverless urban futures: A speculative atlas for autonomous vehicles. New York, NY/London: Routledge.

Mitteregger, M., E. M. Bruck, A. Soteropoulos, A. Stickler, M. Berger, J. S. Dangschat, R. Scheuvens, and I. Banerjee 2020. AVENUE21. Automatisierter und vernetzter Verkehr: Entwicklungen des urbanen Europa. Berlin: Springer Vieweg. https://doi.org/10.1007/978-3-662-61283-5. 
NACTO 2019. Blueprint for Autonomous Urbanism: Second Edition, New York. https://nacto.org/publication/bau2/ (Aug 19, 2020).

POLIS 2019. "Macro Managing Micro Mobility: Taking the long view on short trips," discussion paper. https://www.polisnetwork.eu/document/macromanaging-micromobility/ (Aug 19, 2020).

SAE International 2018. "Surface vehicles recommended practice. J3016. Taxonomy and Definitions for Terms Related to Driving Automation Systems for On-Road Motor Vehicles." https://www.sae.org/ standards/content/j3016_201806/(Aug 19, 2020).

Sasaki 2018. Shifting Gears: An Urbanist's Take on Autonomous Vehicles. https://issuu.com/sasakiassociates/docs/shifting_gears_20180531_-_issue (Aug 19, 2020).

Schaller, B. 2019. Making the Most of the Curb: Managing passenger and parcel pick-up and drop-off on congested city streets, report, Brooklyn, NY. http://www.schallerconsult.com/rideservices/makingmostofcurb.pdf (Aug 19, 2020).

Scheurer, J. 2013. Measuring Copenhagen's public transport accessibility and network performance in a European context. https://www.researchgate.net/publication/286814648_Measuring_Copenhagen\%27s_public_transport_accessibility_and_network_performance_in_a_European_context (Aug 4, 2020).

Schlossberg, M., W. Riggs, A. Millard-Ball, and E. Shay 2018. Rethinking the Street in an Era of Driverless Cars, Urbanism Next, University of Oregon. https://doi.org/10.13140/RG.2.2.29462.04162.

Sinner, M., P. Khaligh, and U. Weidmann 2018. "Consequences of Automated Transport Systems as Feeder Services to Rail. SBB Fund for Research into Management in the Field of Transport," IVT Schriftenreihe (184). https://doi.org/10.3929/ethz-b-000266025.

Statistics Denmark 2016. AREALDK1: Land by land cover, region and unit (DISCONTINUED). https:// www.statbank.dk/statbank5a/default.asp?w=1920 (Aug 4, 2020).

Statistics Denmark 2019a. BIL800: Families disposal of vehicles by region and pattern of disposal. https://www.statbank.dk/statbank5a/default.asp?w=1440 (Aug 4, 2020).

Statistics Denmark 2019b. BIL800: Families disposal of vehicles by region and pattern of disposal. https://www.statbank.dk/statbank5a/default.asp?w=1920 (Aug 4, 2020).

Statistics Denmark 2020. FOLK1A: Population at the first day of the quarter by region, sex, age and marital status. https://www.statbank.dk/KM1 (Aug 4, 2020).

Van Essen, H., X. Rijkee, G. Verbraak, H. Quak, and I. Wilmink 2009. "EU Transport GHG: Routes to 2050? Modal split and decoupling options," Paper 5, draft. https://www.eutransportghg2050.eu/ cms/assets/4823DraftPaper-5.pdf (Aug 19, 2020).

Venturi, R., D. S. Brown, and S. Izenour 1982. Learning from Las Vegas, 5th edition. Cambridge, MA: MIT Press.

Open Access This article is licensed under the terms of the Creative Commons Attribution 4.0 International License (http://creativecommons.org/licenses/by/4.0/), which permits use, sharing, adaptation, distribution and reproduction in any medium or format, as long as you give appropriate credit to the original author(s) and the source, provide a link to the Creative Commons licence and indicate if changes were made.

The images or other third party material in this article are included in the chapter's Creative Commons licence, unless indicated otherwise in a credit line to the material. If material is not included in the chapter's Creative Commons licence and your intended use is not permitted by statutory regulation or exceeds the permitted use, you will need to obtain permission directly from the copyright holder.

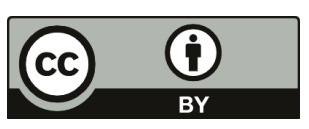

